This is a postprint version of the following published document:

Alonso-Borrego, C., Romero-Medina, A. and Sánchez-Mangas, R. (2017). The impact of public research contracts on scientific productivity. Applied Economics, v. 49, n. 5, pp. 417-432 Avalaible in: https://doi.org/10.1080/00036846.2016.1200181

(C) Taylor \& Francis 


\title{
The impact of public research contracts on scientific productivity
}

\author{
César Alonso-Borrego $\mathbb{1}^{\mathrm{a}}$, Antonio Romero-Medina (10) and Rocío Sánchez-Mangas $\mathbb{( 1}^{\mathrm{b}}$ \\ aDepartment of Economics, Universidad Carlos III, Getafe, Spain; 'Universidad Autónoma de Madrid, Madrid, Spain
}

ABSTRACT

We analyse a competitive research-oriented public programme established in Spain, the Ramon y Cajal Programme, intended to offer contracts in public research centres to high-quality researchers. We study the effects of the programme on the ex post scientific productivity of its recipients, relative to non-granted applicants with comparable curricula at the time of application. The full sample results demonstrate that the programme has a positive and significant effect on the scientific productivity of the recipients, as measured both by the amount of published contribution and by the impact of their publications. Consequently, receiving a contract affects the quantity, but also increases the quality, of the contract recipients' publications.
KEYWORDS

Ramon y Cajal programme; brain gain; research productivity; government research programmes; human capital; policy evaluation; matching

JEL CLASSIFICATION O38; D78; C21; 123; 031

\section{Introduction}

The Ramon y Cajal Programme (RyC programme) is a unique targeted grant-based policy initiative - named after the Spanish neurobiologist and joint winner of the 1906 Nobel Prize in Physiology or Medicine, Santiago Ramón y Cajal - established by the Spanish government in 2001. The programme was designed to attract promising young researchers, both Spanish expatriates and foreign-born, and provide incentives to the Spanish public research centres (PRCs) to improve their strategic planning. The grant recipients were offered a well-defined career path, with a 5-year employment contract at a Spanish PRC, and the opportunity to obtain permanent research positions at the end of the contract (see Sanz-Menéndez et al. 2002; Sanz-Menéndez 2003).

The aim of this article is to evaluate the effect of the RyC programme on the scientific productivity of their beneficiaries. The programme constituted a novel public policy measure in the Science and Technology (S\&T) system, as it shifted the system's focus from training to employability policies (see Cruz-Castro and Sanz-Menéndez 2005). It has become a relevant S\&T instrument in Spain and has attracted attention from the mass media and professional journals (see Bosch 2001a, 2001b; Muñoz-Pinedo et al. 2003) since it began.
The role of public funding in the S\&T system is grounded on the need to correct the market failure behind the public good nature of the scientific knowledge (Nelson 1959; Arrow 1962). Lack of public funding would otherwise make its quantity to be below the optimal social level (Benavente et al. 2012). In addition, Dasgupta and David (1994) point out the need of public funding to yield a balanced mix between scientific and technological research, or between basic and applied research. This is also the case for more innovative but riskier research projects, in which high-quality young researchers are usually involved, and for which public funding can be crucial.

Several initiatives have been implemented at the international level to enhance the participation of young researchers within the S\&T system. The most ambitious initiative promoted by the EU is the Marie Skłodowska-Curie actions - Research Fellowship Program. This programme allows young researchers to apply individually for research fellowships in EU research centres. We can also mention several public postdoctoral programmes in different countries (see Appendix Table A1 for a summary). For example, the Emmy-Noether Programme supports researchers with 2-4 years of postdoctoral experience in Germany. In the Netherlands, the Netherlands Organization for Scientific Research (NWO) provides funding to 
researchers from all nationalities under a number of programmes. In particular, the Innovational Research Incentives Scheme is an instrument to retain talented researchers, offering the Veni, Vidi and Vici grants, which target, respectively, researchers who have just earned their doctorates, researchers with several years of postdoctoral experience and, finally, experienced researchers who have successfully demonstrated that they can develop their own innovative line of research. In the UK, the Economic and Social Research Council (ESRC) offers the Mid-Career Development Fellowships, 2-year fellowships available for established scholars with a research experience of between 5 and 15 years. The RyC programme differs from most of these postdoctoral programmes in its focus on employability rather than training. The Conacyt Chairs for young researchers (Cátedras Conacyt para Jóvenes Investigadores) in Mexico appears as the closest initiative to the RyC programme, promoting researchers up to 40 years old to join ongoing national research projects.

There is a recent literature concerned with the effects of public funding on scientific output. However, it has been mostly focused on the effect of public research grants on the scientific productivity of the research teams. Arora and Gambardella (2005) assess the effect of NSF grants in the field of economics on publication output, adjusted by quality, finding a positive impact for young scholars. Jacob and Lefgren (2011), focusing on a programme from the National Institute of Health in the US, show small positive impact on the number of publications and citations. Chudnovsky et al. (2008) analyse the impact of public research grants in Argentina, also finding positive effects on academic performance, both in terms of the number and quality of publications. Similar findings are reported by Carayol and Lanoe (2013) in France. Beaudry and Allaoui (2012), focusing on research in nanotechnology in Canada, also show that public funding to research groups leads to more published papers. Benavente et al. (2012), using data from a public programme in Chile, find positive effects on the number of publications, but not on the quality of the scientific production. Overall, most of these studies find some positive returns of public funding on scientific production, in terms of quantity or quality or both.

Our article contributes to this literature by assessing the effect of the RyC programme on the scientific productivity of applicants a few years after application. We exploit data on applications in several calls of the programme, provided by the Direccion General de Investigacion of the former Ministry of Science and Innovation. ${ }^{1}$ We complement these data with individual and curricular information on the applicants. We compare successful and unsuccessful applicants using two alternative empirical approaches: linear regression and matching. Our results indicate that contract recipients generated a larger number of published contributions and their scientific impact increased, measured by either the average or the maximum impact of these contributions, with respect to applicants who were not selected by the programme but were comparable in accordance with their curricula at the time of application.

To the best of our knowledge, our article is the first evaluation of the programme's impact on the performance of contract recipients. However, several previous studies have analysed other aspects of the programme. Sanz-Menéndez et al. (2002) undertook a descriptive study of the first call for applications, finding that researchers who were already in the Spanish S\&T system obtained $60 \%$ of the contracts, while the remaining $40 \%$ of contracts were awarded to researchers external to the Spanish S\&T system (two-thirds of whom were Spanish). Cruz-Castro and Sanz-Menéndez (2005) use data from the first three calls to analyse the programme's impact on the spread of information regarding the quality of researchers and PRCs in Spain and ascertain how the programme affected the organizational strategies of the PRCs. They concluded, in the second call, the Program has earned a solid reputation abroad' and increased the chances of those PRCs with a good reputation to attract high-quality young researchers.

Ten years after the first call, the Ministry of Science and Innovation published a Results Report entitled '10 años del Programa Ramón y Cajal' ('Ten years of the Ramon y Cajal Program', DGI 2010).

\footnotetext{
${ }^{1}$ The ministerial arrangements were redesigned after the March 2004 elections, and the Ministry of Science and Technology was eliminated. Its competences were reallocated to the Ministry of Industry, Tourism and Commerce and to the Ministry of Education and Science, which undertook the S\&T competences, including the Ramon y Cajal programme. Since the November 2011 elections, these competences have been the responsibility of the Ministry of Finance and Competitiveness.
} 
The report summarized the results of a survey of the recipients and PRCs involved in the programme and concluded, confirming previous findings, that the evaluation process is generally acknowledged to be objective and transparent, and that the programme has proven to be a good instrument to attract expatriate Spanish researchers.

According to Cruz-Castro and Sanz-Menéndez (2005), the RyC programme provided short-term relief for the key problems of the system that it was intended to address. Particularly it improved the employment opportunities, working conditions and academic career prospects of $\mathrm{PhDs}$. On the supply side, the effects of the programme have been pressing the PRCs to develop strategies for human resource recruitment by research field, and organizing their priorities in terms of competitive research capabilities'. Overall, the professional community has claimed that the programme 'offers a rare opportunity for young scientists trying to gain a foothold in the rigid Spanish academic system' (see Schiermeier 2004). Our results allow us to conclude that the RyC recipients were able to achieve a quality level above that of comparable applicants not selected by the programme.

The remainder of the article is organized as follows. In Section II, we describe the programme and the institutional context in which it was implemented. In Section III, we introduce the main data set of applications and the complementary data set on the applicants' curricular information and preliminary results. In Section IV, we present our empirical approach. In Section V, we evaluate the effectiveness of the programme with respect to the scientific productivity of successful applicants. In Section VI, we summarize the major results and discuss their policy implications, and conclude.

\section{The Spanish S\&T system and the RyC programme}

The Spanish government implemented the RyC programme in 2001 to meet the specific needs of the Spanish S\&T system. At the time it was created, the low level of R\&D investment and the scarcity of researchers were considered two of the central problems in the Spanish S\&T system. In 2001, the share of gross domestic expenditures in $\mathrm{R} \& \mathrm{D}$ relative to GDP in Spain was $0.91 \%$, which contrasts with the averages of $1.76 \%$ in the EU-27 and $2.27 \%$ in the OECD. In that same year, the number of researchers as a share of total employment in Spain amounted to 4.7 per thousand, below the EU-27 average of 5.3 and the OECD average of 6.8 per thousand (see OECD, 2007). However, R\&D personnel in Spain had been increasing rapidly: six years before, in 1995 , the share of R\&D personnel in total employment was only 3.5 per thousand. ${ }^{2}$ As there was no corresponding increase in R\&D funding, the growth in research personnel was primarily achieved through the creation of precarious jobs.

To understand the emergence of this trend, we need to consider the 1970s. At that time, the training of new $\mathrm{PhDs}$ through doctoral programmes was a political objective that became governmental policy (Fernández Esquinas 2002). Since the mid-1980s, there was a steady increase in the availability of 4year public grants to fund doctoral studies (see SanzMenéndez 1997). As a consequence of this policy, in 2000 , there were more than $60,000 \mathrm{PhD}$ students in Spain, and approximately 6000 students received their $\mathrm{PhD}$ every year, these figures being three times those at the beginning of the 1980s (see Cruz-Castro and Sanz-Menéndez 2005).

However, this increase in the supply of $\mathrm{PhDs}$ was not accompanied by a similar increase in job positions for researchers. At the end of the 1990s, access to a permanent research position or a promotion became more difficult than had been previously. The labour market for graduate students and experienced PhDs lacked a career path. Fellowships (typically tied to project funding) became the regular labour relationship. Therefore, the Spanish labour market for researchers in the late 1990s was characterized by both a very high proportion of temporary jobs and a low expenditure per researcher (CruzCastro and Sanz-Menéndez 2005). The two consecutive Spanish National Plans for Scientific Research, Development and Technological Innovation, for the 2000/03 and 2004/07 periods, were explicitly purposed for 'Development of Human Resources' (OCT 1999, 12; CICIT 2003, 17), with the hiring and recruitment of highly skilled professionals in

\footnotetext{
${ }^{2}$ According to Cruz-Castro and Sanz-Menéndez (2005), part of this increase might be due to statistical adjustment. Since 2000, doctoral and postdoctoral personnel with fellowships (but not contracts) are counted as researchers.
} 
public and private research centres among their objectives.

The RyC programme was born to be one of the instruments to fulfil the objectives of the 2000/03 and 2004/07 National Plans. In particular, the objectives attributed to the programme were specifically established as follows. First, to ameliorate the working conditions and long-term employment prospects of a sizeable stock of postdoctoral researchers, within the S\&T system, lacking well-defined career paths. Second, to attract numerous Spanish $\mathrm{PhD}$ graduates with high-quality scientific records who, at that time, were working abroad. The programme provided postdoctoral researchers with a point of entry to the Spanish S\&T system in the form of a 5-year contract that mimics a tenure-track position. ${ }^{3}$

The programme was also intended to provide the PRCs with incentives to align their strategic priorities with their human resources practices. This was implemented by establishing a financial co-responsibility scheme between the PRCs and the government. This scheme discouraged the PRCs from training and increasing the stock of researchers without a well-defined career path who were seeking the opportunity to hold positions within the system (Cruz-Castro and Sanz-Menéndez 2005). Another concern, held both by legislators and in the public arena, was the need to eliminate the favouritism that prevailed in Spanish PRCs (see Bosch 2001b). This concern was crucial in determining the selection procedures accomplished in the programme.

When the RyC programme was launched in 2001, there was a pervasive perception, spread by the mass media, of a significant brain drain on the Spanish S\&T system and a belief that many Spanish $\mathrm{PhD}$ graduates working abroad could be enticed to return if they were provided with improved career opportunities. At the same time, a large amount of highquality young researchers were already in the Spanish R\&D system under temporary positions (Alonso-Borrego et al. 2013)

The first call for applications by the RyC programme attracted approximately 2800 applicants and offered 800 contracts, with a total annual expenditure of 35 million euros. The recipients would receive a 5-year contract with an annual wage of nearly 29,000 euros, similar to the wage of a newly tenured professor ('profesor titular') in Spanish PRCs. In the second and third calls, in 2002 and 2003, 500 and 700 contracts were offered, respectively, attracting more than 2500 applications in each call. ${ }^{4}$ The number of contracts offered decreased substantially after 2003 .

To ensure a transparent selection process and prevent the possibility of favouritism, the selection procedure was centralized in an evaluation agency, the 'Agencia Nacional de Evaluación y Prospectiva' (ANEP). This procedure, centralized and external to the PRCs, was a novel feature of the public policy's design. Its success relied on the involvement of the PRCs, which agreed to be excluded from the selection process while co-financing the hiring of the selected researchers. Despite its transparency, candidate eligibility was subject to the endorsement of the PRCs in the first two calls: applicants were required to obtain an endorsement letter from at least one PRC, which committed the PRC to hire her if selected. This feature attracted international attention (see Bosch 2001b), and Anna Birulés, then the Minister of Science and Technology, reported that some PRCs were jeopardizing the programme by only endorsing local candidates. This endorsement requirement, the effects of which were analysed by Alonso-Borrego et al. (2013), became optional in the 2003 call and was completely eliminated in the 2004 call.

The ANEP appraised all eligible researchers through a peer-review process, primarily based on the candidates' scientific records but also on their potential prospects. $^{5}$ For this purpose, the evaluation agency formed 24 evaluation committees comprising national and international experts, one for each research field. The evaluation committees were entrusted to rank the candidates, yet the allocation of contracts among research areas was determined ex post by a selection committee appointed by the government. Such allocation was determined on technical grounds while accounting for the priorities established by the National R\&D and Innovation Plan, as well as the

\footnotetext{
${ }^{3}$ This programme was complemented with the Juan de la Cierva programme, oriented to researchers in an earlier stage of their career. It gave the possibility to researchers within 3 years after their $\mathrm{PhD}$ to join a research group in Spain for 3 years.

${ }^{4}$ See Alonso-Borrego et al. (2013). It must be noted that applicants could apply to several areas, and hence the number of applications was even higher. However, most applicants, especially in the first call, only submitted a single application.

${ }^{5}$ In the first three calls (2001-2003), the curricular merits of the candidate accounted for $70 \%$ of the assessment, while the candidate's submitted scientific proposal and other merits (such as research stays in outstanding centres and letters of reference) each accounted for $15 \%$.
} 
demands of the different PRCs and the relative quality of researchers according to international standards (see Cruz-Castro and Sanz-Menéndez 2005).

Four years after each call, the performance of each programme recipient during the benefit period was evaluated by the ANEP on the basis of her scientific contributions generated until then. A positive evaluation implied the possibility of receiving a new contract that facilitated her access to a tenured contract at the PRC. According to the Ministry of Science and Innovation, more than $90 \%$ of the recipients reached permanent positions when the RyC contracts finish. Among them, more than $85 \%$ stay at the same PRC that host them under the RyC programme (DGI 2010).

Finally, there is evidence of an inflow of new hiring in the Spanish R\&D system during our period of study. Cruz-Castro and Sanz-Menéndez (2015) show that 'between 1998/99 and 2010/11, the stock of academic staff in Spanish public universities increased by almost 29,100 (from 79,700 to $108,800)^{\prime}$. In the first 10 calls of the RyC programme, between 2001 and 2010, the number of different applicants amounted to 11,658 researchers (DGI 2010), a figure much below the aforementioned increase of researchers in public universities. In fact, in the Spanish Public S\&T system, researchers within PRCs are much likely to stay within them. Sanz-Menéndez, Cruz-Castro, and Alva (2013) point out that 'our system is similar to some others (e.g., Canada) characterized by an association between permanence and tenure (Stewart, Ornstein, and Drakich 2009) in which virtually all academics that stay in an institution eventually get tenure'. This feature, together with the huge increase in the staff of researchers during the period, suggests that most of the RyC beneficiaries and their comparable nonsuccessful applicants (those with comparable CVs at the time of application) were linked to PRCs and remained linked to them at least during these years.

\section{Preliminary evidence on the programme}

The main data set, provided by the Dirección General de Investigación of the Spanish Ministry of Education, records all applications during the first seven calls of the programme, from 2001 to 2007. We excluded observations with missing values for individual characteristics, which represent less than $1 \%$ of all observations. Information on each applicant includes her research area, the institution and year in which she earned her $\mathrm{PhD}$, her country of residence and nationality, and the score received in the assessment process and whether she was granted a contract. We concentrate our analysis on the second and the third calls, in 2002 and 2003, for the following reasons. First, the first call, in 2001, presents several particular characteristics, which might reduce the comparability of its applications with those of subsequent calls (AlonsoBorrego et al. 2013). Second, the eligibility conditions, which were similar in 2002 and 2003, were changed in 2004. ${ }^{6}$

In Table 1, we provide the distribution of applications and contracts for these 2 years, broken down by gender, $\mathrm{PhD}$ tenure and research area. The sample has been restricted to those applicants who applied to a single area. Furthermore, we have excluded applications on arts \& humanities, given that during the period considered disciplines in this area hardly followed international standards. Consequently, we have chosen 22 out of the 24 original areas designated by the ANEP. These 22 areas have been aggregated into nine broader areas. ${ }^{7}$ The first six areas correspond to experimental disciplines (physics, earth sciences, chemistry, agriculture, biomedical and engineering), followed by mathematics, economics and social sciences \& law.

Experimental sciences account for more than $85 \%$ of applications and more than $90 \%$ of contracts. The reason for this allocation of contracts across research areas are the $R \& D$ priorities established in the National R\&D and Innovation Plan.

We observe that applications are dominated by men. The gender distribution across research areas (not reported here) is highly unequal. Physics and engineering are strongly dominated by men, amounting to $80 \%$ of applicants. In chemistry, men represent approximately $60 \%$ of applicants. However, social sciences and biomedical sciences are balanced in terms of gender. With respect to

\footnotetext{
${ }^{6}$ Until 2003, applicants were required to have a PhD and a minimum of an 18-month research stay, at a research centre other than that from which the applicant's college degree was obtained. Since 2004, applicants were required to have earned their PhD in the last 10 years and a minimum 2 years postdoctoral stay in a different research centre than that from which her PhD was obtained.

${ }^{7}$ The correspondence with the areas designated by the ANEP is reported in Appendix Table A2 .
} 
Table 1. Distribution of applications and contracts: absolute and relative (\%) frequencies in each category.

\begin{tabular}{lrrrr}
\hline & Applications & \multicolumn{2}{c}{ Contracts } \\
\hline & 2876 & & 879 & \\
Gender & & & & \\
$\quad$ Female & 1167 & 42.6 & 302 & 36.0 \\
$\quad$ Male & 1574 & 57.4 & 537 & 64.0 \\
PhD tenure (years) & & & & \\
$\quad$ Up to 2 & 677 & 24.7 & 157 & 18.9 \\
3-6 & 1248 & 45.6 & 415 & 49.8 \\
$\quad$ More than 6 & 812 & 29.7 & 261 & 31.3 \\
Research area & & & & \\
Physics & 249 & 8.7 & 66 & 7.5 \\
Earth sciences \& ecology & 320 & 11.1 & 90 & 10.2 \\
$\quad$ Chemistry & 498 & 17.3 & 186 & 21.2 \\
Agriculture, livestock and fishery & 349 & 12.1 & 90 & 10.2 \\
Biomedical sciences & 815 & 28.3 & 261 & 29.7 \\
$\quad$ Engineering \& computing sciences & 263 & 9.1 & 113 & 12.9 \\
$\quad$ Mathematics & 117 & 4.1 & 28 & 3.2 \\
$\quad$ Economics & 84 & 2.9 & 21 & 2.4 \\
$\quad$ Social sciences \& law & 181 & 6.3 & 24 & 2.7 \\
\hline
\end{tabular}

Data from the second (2002) and third (2003) calls.

Sample of applicants who applied to a single area.

the time elapsed since receiving their $\mathrm{PhD}$, the majority of applicants earned their $\mathrm{PhD}$ within 36 years before the call. Additionally, the success rate is higher for men than for women.

The curricular information has been collected from a complementary data source, the free online resource Publish or Perish (Harzing 2007). Publish or Perish retrieves academic contributions by author using the Google Scholar database, which provides the title, source, year and authors of the contribution. Google Scholar is generally praised for its speed (Bosman et al. 2006) and high correlation with alternative bibliometric sources (see Harzing 2013; and Harzing and van der Wal 2008; for a comparison of citation analyses using different data sources). Whenever the contribution was published in a scientific journal, the journal information is also reported. For each applicant, we measure her number of distinct contributions and, among these, the number of published papers.

To assess the quality of each contribution, we use the Journal of Citation Reports (JCR), which provides the impact factors of the international journals listed in its database. A journal's impact factor is calculated on the basis of the average number of citations received by the contributions published in that journal. We use the JCR impact factors in 2006 to measure both the quality of each candidate and the quality of the centre from which each candidate earned her $\mathrm{PhD}$, defined as the average number of citations to all the contributions published in JCR journals by all researchers affiliated with the centre. We consider the journal impact factors from a single year to guarantee the comparability between contributions published in different years. The curricular information is updated until 2007.

We use three measures of the scientific quality of each applicant: her number of contributions listed in the JCR database, the average impact factor of her JCR publications and the maximum impact factor among the JCR journals in which she has published. The two impact factor measures are based on the corresponding impact of the journal in which she published each contribution.

In Table $2 \mathrm{~A}$, we summarize the curricular information of applicants at the time of application by contract status, reporting the mean and SD, as well as the sample median, the 75th and the 90th quantiles. Furthermore, we break down the sample by two applicants' characteristics: gender and time elapsed since $\mathrm{PhD}$ receipt. ${ }^{8}$ For all categories considered, we observe that, at the time of the call, contract recipients have, on average, more published contributions and a greater scientific impact (either average or maximum impact) than non-recipients. Interestingly, we find that the mean and the distribution quantiles of these three quality measures are slightly higher for women than for men. We have performed mean comparison tests of the three quality measures between granted and non-granted applicants for the whole sample, as well as splitting the sample by gender and by $\mathrm{PhD}$ tenure. In all cases, the differences are statistically significant at the usual levels.

In Table 2B, we summarize the curricular information of applicants at the time of application by contract status and by research areas. Regarding our measures of the applicants' scientific quality, the empirical distributions differ substantially depending on the contract status. Specifically, those receiving a contract tend to have a larger number of papers and a greater impact than those without a contract. The mean comparison tests we have performed of the three quality measures between granted and non-granted applicants show statistically significant differences at the usual levels in all

\footnotetext{
${ }^{8}$ The estimation results in Alonso-Borrego et al. (2013) indicate that applicant's curriculum, measured by the average impact factor of her contributions, the scientific quality of the centre from which she earned her $\mathrm{PhD}$, and her PhD tenure, increase the probability of receiving a contract.
} 
Table 2. Curricular information at time of application by contract status (yes/no) - means, SDs and quantiles of the empirical distribution: (A) by gender and PhD tenure and (B) by research areas.

\begin{tabular}{|c|c|c|c|c|c|c|c|c|c|c|c|}
\hline \multirow[b]{2}{*}{ All } & & \multicolumn{2}{|c|}{ Number of papers } & \multicolumn{2}{|c|}{ Average IF } & \multicolumn{2}{|c|}{ Maximum IF } & \multicolumn{2}{|c|}{ Rank Average IF } & \multicolumn{2}{|c|}{ Rank Maximum IF } \\
\hline & & Yes & No & Yes & No & Yes & No & Yes & No & Yes & No \\
\hline \multicolumn{12}{|l|}{ (A) } \\
\hline & Mean & 2.3 & 1.3 & 1.9 & 1.1 & 3.3 & 1.7 & 37.5 & 25.8 & 40.1 & 27.9 \\
\hline & SD & $(4.1)$ & $(2.9)$ & (3.3) & $(2.1)$ & (6.6) & $(4.1)$ & $(41.8)$ & $(36.8)$ & $(44.4)$ & (39.5) \\
\hline & q50 & 0 & 0 & 0.0 & 0.0 & 0.0 & 0.0 & 1 & 1 & 1 & 1 \\
\hline & q75 & 3 & 1 & 2.9 & 1.7 & 4.3 & 2.0 & 86 & 64 & 93 & 72 \\
\hline & q90 & 7 & 5 & 5.4 & 3.6 & 7.9 & 5.3 & 95 & 89 & 98 & 95 \\
\hline \multirow{5}{*}{ Female } & Mean & 2.5 & 1.6 & 2.2 & 1.2 & 4.2 & 2.0 & 42.1 & 29.2 & 44.7 & 31.3 \\
\hline & SD & $(4.3)$ & $(3.2)$ & (3.2) & $(2.2)$ & (7.6) & $(4.5)$ & $(43.0)$ & $(38.7)$ & $(45.4)$ & (41.3) \\
\hline & q50 & 0 & 0 & 0.2 & 0.0 & 0.0 & 0.0 & 2 & 1 & 1 & 1 \\
\hline & q75 & 4 & 2 & 3.6 & 2.3 & 5.2 & 2.8 & 88 & 72 & 94 & 82 \\
\hline & q90 & 7 & 5 & 6.1 & 3.9 & 10.9 & 5.8 & 96 & 92 & 99 & 97 \\
\hline Male & Mean & 2.1 & 1.2 & 1.7 & 0.9 & 2.9 & 1.5 & 35.5 & 23.3 & 37.8 & 25.3 \\
\hline & SD & $(4.0)$ & (2.7) & (3.3) & (2.9) & (5.9) & (3.9) & $(41.0)$ & $(35.2)$ & $(43.7)$ & (38.0) \\
\hline & q50 & 0 & 0 & 0.0 & 0.0 & 0.0 & 0.0 & 1 & 1 & 1 & 1 \\
\hline & q75 & 3 & 1 & 2.6 & 1.3 & 3.8 & 1.4 & 81 & 54 & 90 & 64 \\
\hline & $q 90$ & 6 & 4 & 5.2 & 3.5 & 7.7 & 4.9 & 95 & 87 & 98 & 94 \\
\hline$\leq 2$ years & Mean & 0.9 & 0.6 & 1.3 & 0.6 & 1.8 & 0.8 & 25.9 & 16.4 & 26.9 & 17.4 \\
\hline & SD & $(2.2)$ & (1.9) & (3.3) & $(1.8)$ & $(5.2)$ & $(2.3)$ & $(37.8)$ & $(31.0)$ & $(39.1)$ & (32.8) \\
\hline & q50 & 0 & 0 & 0.0 & 0.0 & 0.0 & 0.0 & 1 & 1 & 1 & 1 \\
\hline & q75 & 1 & 0 & 1.3 & 0.0 & 1.3 & 0.0 & 62 & 1 & 63 & 1 \\
\hline & q90 & 3 & 2 & 3.5 & 2.2 & 4.7 & 2.8 & 94 & 78.5 & 95 & 85 \\
\hline $3-6$ years & Mean & 2.3 & 1.2 & 2.1 & 1.1 & 3.7 & 1.6 & 39.7 & 26.6 & 42.3 & 28.5 \\
\hline & SD & (3.7) & $(2.5)$ & (3.6) & (2.1) & (6.9) & (3.9) & $(42.2)$ & $(37.2)$ & $(44.6)$ & (39.7) \\
\hline & q50 & 0 & 0 & 0.0 & 0.0 & 0.0 & 0.0 & 1 & 1 & 1 & 1 \\
\hline & q75 & 3 & 1 & 3.1 & 1.8 & 4.5 & 2.3 & 87 & 65 & 94 & 73 \\
\hline & q90 & 7 & 4 & 6.1 & 3.9 & 10.4 & 5.4 & 95 & 89 & 99 & 95 \\
\hline$>6$ years & Mean & 2.9 & 2.1 & 2.0 & 1.5 & 3.7 & 2.6 & 41.4 & 33.1 & 44.5 & 36.3 \\
\hline & SD & $(4.9)$ & (3.8) & $(2.7)$ & $(2.4)$ & (6.9) & (5.6) & $(42.6)$ & $(39.2)$ & $(45.5)$ & (42.5) \\
\hline & q50 & 0 & 0 & 0.0 & 0.0 & 0.0 & 0.0 & 2 & 1 & 1 & 1 \\
\hline & q75 & 4 & 3 & 3.5 & 2.7 & 4.9 & 3.8 & 88 & 77 & 94 & 88 \\
\hline & q90 & 8 & 6 & 5.5 & 4.2 & 7.8 & 6.1 & 95 & 93 & 98 & 97 \\
\hline (B) & & & & & & & & & & & \\
\hline Physics & Mean & 1.7 & 0.8 & 2.1 & 0.8 & 2.6 & 1.1 & 39.8 & 21.6 & 42.0 & 22.8 \\
\hline & SD & $(2.4)$ & $(1.8)$ & (3.1) & $(1.7)$ & $(4.4)$ & $(2.3)$ & $(42.5)$ & $(35.7)$ & $(44.2)$ & (37.4) \\
\hline & q50 & 0.5 & 0 & 0.1 & 0.0 & 0.1 & 0.0 & 4.5 & 1 & 4.5 & 1 \\
\hline & q75 & 3 & 1 & 4.1 & 0.9 & 5.4 & 0.9 & 92 & 41 & 94 & 41 \\
\hline & q90 & 5 & 3 & 5.8 & 3.7 & 7.1 & 5.4 & 95 & 90 & 97 & 94 \\
\hline Earth sciences & Mean & 2.2 & 1.4 & 1.6 & 0.9 & 2.5 & 1.5 & 37.4 & 28.4 & 40.7 & 31.0 \\
\hline & SD & (3.6) & $(2.9)$ & (3.4) & (1.4) & $(4.8)$ & (3.7) & $(42.1)$ & (37.3) & $(45.6)$ & (40.3) \\
\hline & q50 & 0 & 0 & 0.0 & 0.0 & 0.0 & 0.0 & 1 & 1 & 1 & 1 \\
\hline & q75 & 4 & 2 & 2.4 & 1.7 & 3.4 & 1.9 & 81 & 68 & 93 & 76 \\
\hline & $\mathrm{q} 90$ & 7.5 & 5 & 3.7 & 2.8 & 6.3 & 4.2 & 95 & 90 & 98 & 94 \\
\hline Chemistry & Mean & 2.8 & 1.6 & 1.8 & 1.0 & 2.7 & 1.4 & 43.5 & 28.0 & 47.0 & 30.4 \\
\hline & SD & $(4.0)$ & $(3.0)$ & $(2.6)$ & $(1.5)$ & $(4.0)$ & (2.3) & $(40.4)$ & $(36.4)$ & $(43.3)$ & (39.2) \\
\hline & q50 & 1 & 0 & 1.6 & 0.0 & 1.6 & 0.0 & 59.5 & 1 & 69.5 & 1 \\
\hline & q75 & 5 & 2 & 2.9 & 2.5 & 4.3 & 2.8 & 82 & 67 & 91 & 73.5 \\
\hline & q90 & 8 & 5 & 4.1 & 3.6 & 7.7 & 4.5 & 93 & 84 & 96 & 93 \\
\hline Agriculture & Mean & 2.1 & 1.5 & 1.6 & 1.2 & 2.8 & 1.8 & 48.8 & 36.4 & 50.8 & 37.4 \\
\hline & SD & (3.1) & (3.1) & $(2.4)$ & $(2.0)$ & (5.5) & (3.9) & $(45.3)$ & $(43.9)$ & $(46.8)$ & $(45.1)$ \\
\hline & $q 50$ & 1 & 0 & 1.1 & 0.0 & 1.1 & 0.0 & 67.5 & 1 & 69 & 1 \\
\hline & q75 & 3 & 2 & 2.6 & 2.1 & 3.4 & 2.5 & 97 & 90 & 99 & 97 \\
\hline & q90 & 5.5 & 4 & 3.9 & 3.4 & 5.8 & 4.8 & 99 & 99 & 99 & 99 \\
\hline Biomedical & Mean & 3.2 & 2.1 & 3.2 & 1.9 & 6.4 & 3.2 & 41.5 & 32.6 & 44.1 & 36.2 \\
\hline & SD & (5.7) & (3.8) & $(4.3)$ & (3.1) & (9.7) & $(6.3)$ & $(44.1)$ & $(38.8)$ & $(46.7)$ & (42.6) \\
\hline & $\mathrm{q} 50$ & 0 & 0 & 0.0 & 0.0 & 0.0 & 0.0 & 1 & 1 & 1 & 1 \\
\hline & q75 & 5 & 3 & 5.4 & 3.4 & 8.1 & 4.9 & 90 & 77 & 95 & 88 \\
\hline & q90 & 8 & 7 & 8.8 & 4.9 & 26.7 & 8.0 & 95 & 89 & 99 & 96 \\
\hline Engineering & Mean & 0.4 & 0.2 & 0.3 & 0.2 & 0.4 & 0.2 & 15.8 & 8.3 & 16.1 & 8.8 \\
\hline & SD & $(0.9)$ & $(0.8)$ & $(0.9)$ & $(0.6)$ & $(1.2)$ & $(0.8)$ & (31.3) & (21.8) & $(32.5)$ & (23.0) \\
\hline & q50 & 0 & 0 & 0.0 & 0.0 & 0.0 & 0.0 & 1 & 1 & 1 & 1 \\
\hline & q75 & 0 & 0 & 0.0 & 0.0 & 0.0 & 0.0 & 2 & 1 & 1 & 1 \\
\hline & q90 & 1 & 1 & 1.4 & 0.5 & 1.6 & 0.6 & 79 & 36.5 & 89 & 43.5 \\
\hline Mathematics & Mean & 1.2 & 0.5 & 0.3 & 0.2 & 0.4 & 0.2 & 23.5 & 13.7 & 25.9 & 15.4 \\
\hline & SD & $(2.0)$ & $(1.2)$ & $(0.5)$ & $(0.3)$ & $(0.5)$ & $(0.4)$ & $(30.1)$ & $(23.0)$ & $(32.8)$ & (26.3) \\
\hline & q50 & 0 & 0 & 0.0 & 0.0 & 0.0 & 0.0 & 1 & 1 & 1 & 1 \\
\hline & q75 & 1.5 & 1 & 0.6 & 0.0 & 0.7 & 0.4 & 41.5 & 24 & 57.5 & 24 \\
\hline & $\mathrm{q} 90$ & 5 & 2 & 1.2 & 0.7 & 1.2 & 0.9 & 80 & 55 & 83 & 67 \\
\hline Economics & Mean & 2.0 & 0.6 & 0.8 & 0.4 & 0.9 & 0.5 & 39.9 & 18.6 & 46.0 & 19.8 \\
\hline
\end{tabular}


Table 2. (Continued).

\begin{tabular}{|c|c|c|c|c|c|c|c|c|c|c|c|}
\hline \multirow[b]{2}{*}{ All } & & \multicolumn{2}{|c|}{ Number of papers } & \multicolumn{2}{|c|}{ Average IF } & \multicolumn{2}{|c|}{ Maximum IF } & \multicolumn{2}{|c|}{ Rank Average IF } & \multicolumn{2}{|c|}{ Rank Maximum IF } \\
\hline & & Yes & No & Yes & No & Yes & No & Yes & No & Yes & No \\
\hline \multirow{8}{*}{ Social sciences } & SD & $(2.0)$ & (1.1) & $(0.9)$ & $(0.9)$ & $(1.0)$ & $(1.2)$ & (34.2) & $(30.3)$ & (36.4) & (32.3) \\
\hline & q50 & 1 & 0 & 0.6 & 0.0 & 0.8 & 0.0 & 38 & 1 & 53 & 1 \\
\hline & q75 & 4 & 1 & 1.0 & 0.4 & 1.0 & 0.4 & 65 & 23 & 67 & 23 \\
\hline & q90 & 5 & 2 & 1.8 & 1.4 & 2.4 & 1.6 & 88 & 79 & 94 & 84 \\
\hline & $\begin{array}{l}\text { Mean } \\
\text { SD }\end{array}$ & $\begin{array}{c}0.5 \\
(1.2)\end{array}$ & $\begin{array}{c}0.2 \\
(0.6)\end{array}$ & $\begin{array}{c}0.5 \\
(1.2)\end{array}$ & $\begin{array}{c}0.1 \\
(0.4)\end{array}$ & $\begin{array}{c}0.6 \\
(1.5)\end{array}$ & $\begin{array}{c}0.1 \\
(0.4)\end{array}$ & $\begin{array}{c}17.0 \\
(30.9)\end{array}$ & $\begin{array}{c}7.7 \\
(20.0)\end{array}$ & $\begin{array}{c}19.2 \\
(34.8)\end{array}$ & $\begin{array}{r}8.0 \\
(20.9)\end{array}$ \\
\hline & q50 & 0 & 0 & 0.0 & 0.0 & 0.0 & 0.0 & 1 & 1 & 1 & 1 \\
\hline & q75 & 0.5 & 0 & 0.2 & 0.0 & 0.2 & 0.0 & 15 & 1 & 15 & 1 \\
\hline & $\mathrm{q} 90$ & 2 & 1 & 1.1 & 0.4 & 3.0 & 0.5 & 63 & 32 & 97 & 33 \\
\hline
\end{tabular}

$q_{j}$ is the jth percentile of the empirical distribution of the corresponding outcome variable.

areas, with the only exceptions of the number of JCR papers in agriculture and engineering and the maximum impact factor in mathematics and economics.

We also find that the three measures of scientific quality differ substantially by area, reflecting differences in the typical number of papers and citations across research fields, and therefore the impact indices are not comparable across areas. To provide a measure of scientific impact that permits comparisons across areas, we constructed the relative rank or position of each researcher with respect to the empirical distribution of impacts of all JCR journals in her research area. We computed the quantile (between 1 and 99) of the corresponding empirical distribution of the journal impact achieved by each researcher given her average and her maximum impact factor, which we have denoted 'rank average IF' and 'rank maximum IF', respectively. For instance, a researcher who published a paper in the journal with the highest impact in her area would have a rank maximum IF of 99 .

The evidence of a larger number of papers as well as a greater impact achieved by contract recipients agrees with the criteria established by the committees in the selection of applicants, which emphasize their scientific quality. However, we observe that for contract recipients the median number of papers and the impact at the time of application is zero in most areas. We believe that selection committees were taking other quality features into consideration at the moment of application that are unobserved in our data set. Specifically, we have measured each applicant's scientific merits using her contributions published in JCR journals up to the year of application. However, unlike the selection committee, we cannot observe papers under revision, forthcoming papers (not yet published in the year of the call) and, to a lesser extent, the quality of the candidate's research agenda, among others. For most areas, we observe strong differences by contract status for the highest quartile of the distribution. In terms of both the average and maximum impact, the highest quartile of researchers with a contract achieve high positions within the impact distribution in their corresponding area, approaching ranks above 85 in all experimental disciplines except engineering. These disciplines amount to $75 \%$ of all contracts. In economics, the highest quartile of researchers rank above 65 . The pattern is substantially different in mathematics and social sciences \& law.

For researchers without a contract, we observe that, in experimental disciplines except engineering, the highest decile of researchers without a contract rank at least 85 in experimental disciplines. This evidence suggests that we can identify a sufficient number of researchers without contracts that are comparable, in terms of our curricular measures, with researchers with contracts. In the case of economics, the highest decile of researchers without a contract are at least ranked by almost 80 . For engineering, mathematics and social sciences \& law, the highest decile of researchers without a contract rank much lower. This suggest that, in terms of curricular quality, the number of available comparable researchers to contract recipients might be much smaller in these areas. This finding might be evidence that most researchers in certain non-experimental disciplines have yet to adapt to international standards. ${ }^{9}$

\footnotetext{
9Jiménez-Contreras, de Moya Anegón, and Delgado López-Cózar (2003) analyse the impact of the national evaluation of researchers' activity in Spain on their research output. They find that 'preference will be given to those articles which are published in journals of recognized prestige that is to say, those journals which occupy a notable position in the lists, organized by scientific field, which appear in the Subject Category Listing of the Journal Citation Reports of the Science Citation Index (Institute of Scientific Information, Philadelphia, PA, USA)'. These criteria are applied to all the research areas except arts \& humanities and law, ' which use alternative criteria' .
} 
The results suggest the quality of the researchers selected and the existence of comparable candidates in most of the research areas considered. However, as reported in Table $2 \mathrm{~B}$, the areas of social sciences \& law and engineering exhibit a shortage of highquality candidates, as reflected, relative to other areas, by the smaller number of papers and the worse ranking in the highest quartile of the distribution of impacts, regardless of the outcome of the application process.

\section{Empirical approach}

We consider the scientific output of applicants in the four years after the call to assess the impact of contract status on the ex post performance of researchers. Given the data constraints, we consider the time horizon selected to be sufficient to test the potential influence of the contract. Moreover, it is consistent with the usual time span the PRCs take to make tenure decisions, and with the maximum length of time required for scientific contributions to undergo a peer-reviewed publication process.

Our relevant policy variable is a binary variable $D_{i}$ indicating whether the individual was granted a $\mathrm{RyC}$ contract, which takes on 1 if the researcher $i$ has been awarded a contract and 0 otherwise. Our concern is whether the contract status affects the researcher's productivity outcome $Y_{i}$ in the 4-year period after the call. We perform the analysis using three alternative outcome variables that measure researchers' scientific performance. These variables are the number of contributions published in journals listed in the JCR, the average impact of such contributions and the maximum impact factor among the JCR journals in which a researcher has published. Additionally, to ease the comparability across areas, we construct the aforementioned normalized impact variables for average and maximum impact, respectively, which consist on the rank or relative position that each researcher would achieve in her research area using the empirical distribution of the impacts of the journals in such area.

For individual $i$, her causal effect would result from the difference between its two potential outcomes depending on whether she received a contract or did not, denoted as $Y_{1 i}$ and $Y_{0 i}$, respectively. If both counterfactual outcomes were observed, the treatment effect, i.e. the impact of the contract for researcher $i$, would simply be $\left(Y_{1 i}-Y_{0 i}\right)$. Using $E$ (.) to denote the mean operator, we could then calculate the average impact of the contract on the population, or the average treatment effect (ATE), as $E\left(Y_{1 i}-Y_{0 i}\right)$ (see Rosenbaum and Rubin 1983), or, concentrating on the subpopulation of contract recipients, the average treatment effect on the treated (ATT) $E\left(Y_{1 i}-Y_{0 i} \mid D_{i}=1\right)$. However, it is well known that as receiving and not receiving a contract are mutually exclusive, for each researcher we only observe either $D_{i}=1$ or $D_{i}=0$, and therefore we only observe her outcome under one of the two situations, i.e.

$$
Y_{i}=Y_{0 i}+\left(Y_{1 i}-Y_{0 i}\right) D_{i}
$$

If the contract status were purely random, and thus independent of the potential outcomes, then the three evaluation measures would be equivalent,

$$
\begin{aligned}
E\left(Y_{1 i}-Y_{0 i}\right) & =E\left(Y_{1 i}-Y_{0 i} \mid D_{i}=1\right) \\
& =E\left(Y_{1 i}-Y_{0 i} \mid D_{i}=0\right)
\end{aligned}
$$

and hence, the average effect of the contract would simply be $E\left(Y_{1 i} \mid D_{i}=1\right)-E\left(Y_{0 i} \mid D_{i}=0\right)$. In this case, a naive mean-difference estimator based on the sample means of the observed outcomes for recipients and non-recipients would consistently estimate the causal effect of the contract. This result also holds under the weaker assumption of mean independence between the contract and the potential outcomes.

However, we know that contract status depends on researchers' characteristics, and therefore, researchers' potential outcomes $Y_{1 i}, Y_{0 i}$ are not independent of the contract status $D_{i}$. To see this, notice that the observed difference in outcomes between recipients and non-recipients can be written as

$$
\begin{aligned}
& E\left(Y_{1 i} \mid D_{i}=1\right)-E\left(Y_{0 i} \mid D_{i}=0\right) \\
& \quad=\mathrm{ATT}+\left[E\left(Y_{0 i} \mid D_{i}=1\right)-E\left(Y_{0 i} \mid D_{i}=0\right)\right]
\end{aligned}
$$

where the second term on the right-hand side of the equation measures the potential selection bias arising because of the differential performance of recipients and non-recipients even in the absence of the contract. Presumably, a naive mean-difference estimator is expected to exacerbate the positive impact of the contract as contract recipients are likely to be more productive than non-recipients even in the absence of the contract. 
As potential outcomes are not independent of contract status, identification requires the availability of individual pre-contract information and assumptions regarding the relationship between contract status and potential outcomes, conditional on such additional information. The main idea is that contract status is purely random for individuals with similar pre-contract information. We consider two alternative approaches: parametric (regression) and non-parametric (matching). We first describe the problem in the regression framework to illustrate how we can circumvent selection bias by exploiting additional information.

We can write the observed outcome for researcher $i$ as a simple linear projection on the contract status,

$$
Y_{i}=\alpha+\rho D_{i}+u_{i}
$$

where the slope $\rho$ is the ATE and $u_{i}$ captures the unobserved deviation of the potential outcomes of researcher $i$. The simple OLS estimator of $\rho$ in (4) yields the aforementioned naive mean-difference estimator based on the sample means of the observed outcome for recipients and non-recipients. This estimator would consistently estimate the ATE provided that the error term is mean-independent of contract status, i.e. $E\left(u_{i} \mid D_{i}\right)=0$. However, we should expect a selection bias between recipients and non-recipients, $E\left(u_{i} \mid D_{i}=1\right) \neq E\left(u_{i} \mid D_{i}=0\right)$ as recipients are expected to be more productive than non-recipients.

The availability of additional variables that contain pre-contract information might allow to circumvent this selection bias. Let $\mathbf{X}_{i}$ be a vector of additional covariates, including the researcher's curricular information and other relevant variables at the time of application. Consider the assumption that, conditional on the covariates included in $\mathbf{X}_{i}$, the potential outcomes are mean-independent of $D_{i}$, i.e.

$$
E\left(Y_{j i} \mid D_{i}, \mathbf{X}_{i}\right)=E\left(Y_{j i} \mid \mathbf{X}_{i}\right) \quad j=0,1 .
$$

This conditional mean-independence assumption is also called 'selection on observables' as it states that $\mathbf{X}_{i}$ determines contract status. We also need to assume parametric specifications for the conditional expectations, given $D_{i}$ and $\mathbf{X}_{i}$, of the unobserved individual deviations of the potential outcomes for recipients and non-recipients. Under such assumptions, we can write the augmented model as

$$
Y_{i}=\alpha+\rho D_{i}+\beta^{\prime} \mathbf{X}_{i}+\gamma^{\prime} D_{i} \mathbf{X}_{i}+u_{i}
$$

where now $E\left(u_{i} \mid D_{i}, \mathbf{X}_{i}\right)=0$. It can be seen that the causal effect for researcher $i$ is equal to $\rho+\gamma^{\prime} \mathbf{X}_{i}$, meaning that it varies with the values of the conditioning variables. To calculate the ATE, we must evaluate this expression at $E\left(\mathbf{X}_{i}\right)$, while to calculate the ATT, it must be evaluated at $E\left(\mathbf{X}_{i} \mid D_{i}=1\right.$ ) (see Wooldridge 2002). Under the above assumptions, OLS estimation of (6) will yield a consistent estimate of the impact of the contract.

As an alternative to regression analysis, we can follow a non-parametric approach and produce matching estimators of the impact of the contract, using the individual pre-contract information mentioned above. If, for individuals with similar precontract information, contract status can be considered as purely random, we can estimate the corresponding counterfactual outcome for each contract recipient using the average outcome for non-recipients with similar pre-contract information. Matching estimators rely on a stronger version of the selection on observables assumption, by which, conditional on $\mathbf{X}_{i}$, treatment status is independent of potential outcomes (see Rosenbaum and Rubin 1983). However, unlike regression analysis, matching estimators do not require parametric assumptions. The conditional independence assumption allows us to analyse our observational data as if they came from a randomized experiment.

Following Abadie and Imbens (2011), we implement bias-corrected matching estimators, which employ a regression adjustment to circumvent the finite-sample bias that arises when the matching is not exact. The matches are directly based on the same curricular covariates used in the regression. There are two reasons why we do not employ a propensity score approach to match treatment and comparison observations. First, given the small number of covariates, we do not have a serious dimensionality problem. Second, and more important, propensity score matching is based on firststep estimates of the unknown propensity score. It is difficult to derive the asymptotic variance of the matching estimator when estimated propensity scores, instead of (unknown) actual propensity scores, are used (see Abadie and Imbens 2009). Moreover, the standard bootstrap variance employed in empirical work is not appropriate 
(Abadie and Imbens 2008). Abadie and Imbens (2011) derive the asymptotic variance for the biascorrected matching estimator that we use, which is implemented in a Stata routine that is fully documented in Abadie et al. (2004).

We have ruled out a regression discontinuity approach after analysing the allocation process of contracts and the data themselves. The major pitfall to implement this procedure is that the assumption of an exogenous rule of assignment does not hold. Namely, there is not an ex ante cut-off such that the score provided by the selection committees in each area determine the contract allocation. Instead, as we have mentioned earlier, the cut-off in each area is endogenously determined after the selection committee establishes the number of contracts to be allocated to each area.

\section{The performance of RyC researchers}

We estimate the causal effects of the contract, conditional on researcher characteristics at the time of application, to overcome the selection bias due to the endogeneity of contract status. The validity of the conditional estimates of the causal effects relies on the absence of unobserved differences across researchers associated with contract status that affect their potential outcomes. The covariates we consider in the empirical analysis are related to the researcher's curricular information at the time of application, the time elapsed since $\mathrm{PhD}$ receipt and her research area. We consider alternative parametric (regression) and non-parametric (matching) procedures using this set of conditioning variables. Regarding the researcher's curricular information, we use the number of JCR papers and the average impact factor. We use a second-order polynomial on these two variables and the cross-product between them. Our measure of causal effect is the ATT, which measures the average effect of the contract for those researchers who actually had a contract. For the sake of comparison, we also calculate the naive unconditional estimates of the impact of the contract in (4), which presumably tend to overestimate the causal effect of the contract on scientific productivity.

In addition to the curricular information of the applicant at the time of application, we also condition on the score achieved by the candidate in the assessment process. While this score is expected to be correlated with the aforementioned curricular information at the time of application, it is also likely to capture further information available to the assessment committee but different than our observed measures of candidate's quality, such as papers under revision, forthcoming papers and the quality of her research agenda.

The main outcomes that we consider to measure scientific productivity in the 4-year period after the application are the number of JCR papers published by the researcher and the scientific impact measure of her JCR contributions during that period. As impact measures, we use the aforementioned average and maximum impact factors, as well as the corresponding normalized measures that yield the rank or relative position that each researcher would achieve within her research area with respect to the empirical distribution of impact of the journals in that area, measured by the percentile that the researcher would reach within this empirical impact distribution.

In Table 3, we report the conditional regression estimates for our five outcome variables. In all cases, the $R^{2}$ is above $40 \%$, showing that the curricular measures at the time of application provide a substantial explanatory power. The polynomial in the number of published papers and the average impact factor exhibits a significant effect, with both variables showing a positive but marginally decreasing effect. The logarithm of the score, however, is only significant for the number of papers. As part of the differential information of the score with respect to the observed curricular information might include papers under revision, its negative effect might be reflecting the failure of part of this potential research in getting published. Finally, the $\mathrm{PhD}$ tenure has a negative effect for young PhDs, but this effect turns out positive for higher $\mathrm{PhD}$ tenures.

In Table 4, we report the estimates of the impact of the contract for contract recipients, using the unconditional (naive) estimators, the conditional regression estimators presented in Table 3 , and the matching estimators. The naive estimates are both positive and significant for every outcome considered. These estimates may suffer from a positive selection bias, which is confirmed by the conditional estimates (both regression and matching) of the causal effects, which employ the researchers' precontract characteristics as covariates. Although both the conditional regression and the matching 
Table 3. Regression results (ATT).

\begin{tabular}{|c|c|c|c|c|c|}
\hline & Number of papers & Average IF & Maximum IF & Rank average IF & Rank maximum If \\
\hline Contract & $\begin{array}{l}0.445^{* * * *} \\
(0.168)\end{array}$ & $\begin{array}{l}0.290^{* * * *} \\
(0.104)\end{array}$ & $\begin{array}{l}0.323^{*} \\
(0.190)\end{array}$ & $\begin{array}{c}3.639^{* *} \\
(1.480)\end{array}$ & $\begin{array}{l}3.906^{* *} \\
(1.553)\end{array}$ \\
\hline $\log ($ score) & $\begin{array}{c}-0.393^{* * *} \\
(0.188)\end{array}$ & $\begin{array}{c}-0.060 \\
(0.089)\end{array}$ & $\begin{array}{c}-0.143 \\
(0.140)\end{array}$ & $\begin{array}{c}-0.289 \\
(1.732)\end{array}$ & $\begin{array}{c}-0.484 \\
(1.831)\end{array}$ \\
\hline \multicolumn{6}{|l|}{ CV (at year of application) } \\
\hline No. of papers & $\begin{array}{l}0.788^{* * * *} \\
(0.156)\end{array}$ & $\begin{array}{l}0.239 * * * \\
(0.060)\end{array}$ & $\begin{array}{l}0.322^{* *} \\
(0.153)\end{array}$ & $\begin{array}{l}8.560^{* * * *} \\
(0.823)\end{array}$ & $\begin{array}{l}10.144 * * * \\
(0.874)\end{array}$ \\
\hline Average IF & $\begin{array}{l}0.175^{* *} \\
(0.094)\end{array}$ & $\begin{array}{l}0.465^{* * *} \\
(0.117)\end{array}$ & $\begin{array}{l}0.594^{* * *} \\
(0.141)\end{array}$ & $\begin{array}{l}10.378^{* * *} \\
(1.166)\end{array}$ & $\begin{array}{l}10.692^{* * *} \\
(1.213)\end{array}$ \\
\hline No. of papers*Average IF & $\begin{array}{l}-0.005 \\
(0.029)\end{array}$ & $\begin{array}{c}0.017 \\
(0.011)\end{array}$ & $\begin{array}{l}0.102^{* * * *} \\
(0.030)\end{array}$ & $\begin{array}{l}-0.506^{* * * *} \\
(0.100)\end{array}$ & $\begin{array}{l}-0.624^{* * * *} \\
(0.104)\end{array}$ \\
\hline No. of papers ${ }^{2}$ & $\begin{array}{c}0.001 \\
(0.012)\end{array}$ & $\begin{array}{c}-0.012^{* * *} \\
(0.004)\end{array}$ & $\begin{array}{c}-0.016 \\
(0.010)\end{array}$ & $\begin{array}{l}-0.259 * * * \\
(0.047)\end{array}$ & $\begin{array}{l}-0.296^{* * *} \\
(0.049)\end{array}$ \\
\hline Average $\mathrm{IF}^{2}$ & $\begin{array}{c}-0.009^{*} \\
(0.005)\end{array}$ & $\begin{array}{c}-0.012 \\
(0.010)\end{array}$ & $\begin{array}{l}-0.027^{* * *} \\
(0.009)\end{array}$ & $\begin{array}{l}-0.338^{* * * *} \\
(0.062)\end{array}$ & $\begin{array}{l}-0.346^{* * *} \\
(0.064)\end{array}$ \\
\hline PhD tenure & & & & & \\
\hline No. of years since $\mathrm{PhD}$ & $\begin{array}{l}-0.174^{* * *} \\
(0.036)\end{array}$ & $\begin{array}{l}-0.058^{* * *} \\
(0.015)\end{array}$ & $\begin{array}{c}-0.107^{* * *} \\
(0.028)\end{array}$ & $\begin{array}{c}-1.788^{* * *} \\
(0.357)\end{array}$ & $\begin{array}{c}-1.929 * * * \\
(0.368)\end{array}$ \\
\hline No. of years since $\mathrm{PhD}^{2}$ & $\begin{array}{l}0.005^{* * * *} \\
(0.001)\end{array}$ & $\begin{array}{l}0.002^{* * * *} \\
(0.001)\end{array}$ & $\begin{array}{l}0.003^{* * * *} \\
(0.001)\end{array}$ & $\begin{array}{l}0.061^{* * * *} \\
(0.016)\end{array}$ & $\begin{array}{l}0.065^{* * *} \\
(0.017)\end{array}$ \\
\hline Constant & $\begin{array}{l}2.359 * * * \\
(0.771)\end{array}$ & $\begin{array}{l}0.794^{* *} \\
(0.373)\end{array}$ & $\begin{array}{l}1.351^{* * * *} \\
(0.586)\end{array}$ & $\begin{array}{l}15.877^{* *} \\
(7.544)\end{array}$ & $\begin{array}{l}17.370^{* *} \\
(7.969)\end{array}$ \\
\hline No. of observations & 2734 & 2734 & 2734 & 2734 & 2734 \\
\hline$R^{2}$ & 0.504 & 0.460 & 0.421 & 0.466 & 0.485 \\
\hline
\end{tabular}

Robust SEs in parentheses.

Binary variables for research areas included in all estimations.

$*^{*}, * *{ }^{* * *}$ Significant at $10 \%, 5 \%$ and $1 \%$ levels, respectively.

estimates are positive too, their magnitudes are much lower than the naive estimates. Further, the magnitudes of the regression and matching estimates are very similar, yet matching estimates tend to be higher. For all of the quantity (the number of JCR papers) and the quality (impact) measures, the ATT is positive and significant. These results indicate that the contract would have, on average, a positive effect on both the quantity and quality of the scientific production of a randomly chosen applicant. Using either of the two rank measures, we find that, on average, the receipt of a contract causes recipients to

Table 4. Full sample estimates of the causal effect of the contract (ATT).

\begin{tabular}{lccc}
\hline & Naive & Regression & Matching \\
\hline Outcome & & & \\
Number of papers & $0.99^{* * *}$ & $0.44^{* * *}$ & $0.60^{* * *}$ \\
& $(0.19)$ & $(0.17)$ & $(0.16)$ \\
Average IF & $0.71^{* * *}$ & $0.29^{* * *}$ & $0.32^{* * *}$ \\
& $(0.12)$ & $(0.10)$ & $(0.11)$ \\
Maximum IF & $1.16^{* * *}$ & $0.32^{*}$ & $0.51^{* * *}$ \\
& $(0.20)$ & $(0.19)$ & $(0.19)$ \\
Rank average IF & $10.84^{* * *}$ & $3.64^{* *}$ & $3.89^{* *}$ \\
& $(1.64)$ & $(1.48)$ & $(1.78)$ \\
Rank maximum IF & $11.54^{* * *}$ & $3.91^{* *}$ & $3.80^{* *}$ \\
& $(1.74)$ & $(1.55)$ & $(1.89)$ \\
\hline
\end{tabular}

See notes to Table 3.

Matching procedure is implemented with replacement, using four matches per observation, and the Mahalanobis metric to measure the distance among covariate values. shift 4 percentiles upwards within the impact distribution.

In Table 5, we have calculated the causal effects (in percentages) of the contract on each outcome variable, using the sample average of the corresponding outcome at the time of application. Looking at regression and matching estimates, contract recipients produce on average between $20 \%$ and $26 \%$ papers more than in the absence of the contract, and increase their average impact by between $15 \%$ and $17 \%$, and their maximum impact by between $10 \%$ and $15 \%$.

Our results contribute to the empirical literature on the effects of public funding on scientific productivity. In the same fashion that it has been found a positive effect of public funding on the scientific productivity of research groups, we find a positive and significant effect of publicly funded contracts on the scientific productivity of young researchers.

We have also considered alternative estimates, using alternative conditioning sets and a longer time span after the application, to evaluate the sensitivity of the results. Specifically, we have considered additional conditioning variables, such as gender, as well as the inclusion of the maximum IF among the curricular measures and different degrees of the polynomial in the curricular measures. The results (not reported here but available upon 
Table 5. Percentage causal effect of the contract (relative to the outcome at the time of application).

\begin{tabular}{lccc}
\hline & Naive & Regression & Matching \\
\hline Outcome & & & \\
Number of papers & $61.40^{* * *}$ & $19.63^{* * *}$ & $26.53^{* *}$ \\
Average IF & $53.91^{* * *}$ & $15.36^{* * *}$ & $16.85^{* * *}$ \\
Maximum IF & $53.23^{* * *}$ & $9.72^{*}$ & $15.37^{* * *}$ \\
Rank average IF & $36.88^{* * *}$ & $9.70^{* *}$ & $10.37^{* *}$ \\
Rank maximum IF & $36.51^{* * *}$ & $9.75^{* *}$ & $9.48^{* *}$ \\
\hline
\end{tabular}

See notes to Tables 3 and 4.

The reference value is the average of the outcome variable at time of application.

request) can be summarized as follows. We find that the gender was not significant and did not increase the explanatory power of the regression estimates, and the estimated causal effects remain similar. ${ }^{10}$ Moreover, the selection of either the curricular measures or the functional form does not alter the main empirical results. When we considered the longer 5year time span after the application, the qualitative results are unchanged. ${ }^{11}$ However, as we were only able to gather curricular information until 2007, we can only use applicant data from 2002, and hence the precision of the estimates is reduced. Overall, our results appear to be robust to the choice of conditioning variables, functional form and time span after application. We have also considered separate estimation by research areas. The major qualitative results remain, yet estimates become much more imprecise due to the small sample size. ${ }^{12}$

\section{Conclusions}

The RyC programme constituted a novel policy measure and has become a relevant S\&T instrument in Spain. The programme was designed to improve the working conditions and long-term employment prospects of a sizeable stock of postdoctoral researchers within the S\&T system and attract numerous Spanish $\mathrm{PhD}$ graduates with high-quality scientific records who were working abroad.

Our article studies whether a RyC contract affects the research output of the recipients a few years later. We analysed the effect of the programme on the productivity of the selected researchers and compared them with scholars with similar curricular characteristics that were not awarded a RyC contract. We employed two alternative approaches to estimate the causal effect of the contract: conditional regression and matching procedures. Overall, the results provided by the two methods are similar. They indicate that the RyC contract allowed their recipients to achieve a quality level above that of comparable applicants not selected by the programme, both in terms of the quantity (number of papers) and, more importantly, the quality (average and maximum impact). This is an important result, which supports policies designed to increase the stock of human resources in scientific research to raise the international impact of the Spanish $R \& D$ system.

The programme also had favourable effects on the Spanish S\&T system. We have summarized the contributions of previous researchers who established that the programme has earned a solid reputation abroad and increased the chances of PRCs with solid reputations to attract high-quality young researchers. It has also provided short-term improvements in the employment opportunities, working conditions and academic career prospects of $\mathrm{PhDs}$.

However, in recent years, the S\&T system has failed to provide employment opportunities for all of the researchers who, in the spirit of a tenure-track position, were evaluated positively at the end of the RyC contract. The first researchers selected finished their contracts in 2007 , coinciding with the beginning of the Spanish economic crisis. This has limited many of these researchers' prospects within the Spanish S\&T system, jeopardizing the programme's achievements in previous years. This has generated a perception that Spain has shifted from aiming at 'premier league' status (Schiermeier 2004) to "scientific suicide' (Moro-Martin 2012). Even though the number of contracts has been substantially reduced in the last calls, the RyC programme has been maintained even in the aftermath of the crisis. It is widely

\footnotetext{
${ }^{10}$ The variable gender was missing for a fraction of our sample, so that we have preferred to report the results with the large sample size, thus excluding gender.

11 The effect of the contract on the number of papers remains positive and significant, with estimated coefficients between 0.94 and 1.24 for regression and matching, respectively. We also find positive estimated effects of 0.22 and 0.72 for the corresponding average and maximum impact factor. The estimated effect on the rank measures is also positive and significant, amounting to 6 percentiles across the distribution of impacts.

${ }^{12}$ The estimated effects on both the number of papers and the different quality measures are significantly positive for physics, earth sciences, chemistry and agriculture. These four areas represent almost $60 \%$ of the applications and more than half of the contracts, among experimental areas. In the case of medicine and engineering (the other two experimental areas) and in the non-experimental areas, we do not find significant effects. Overall, the reported full sample results are mostly driven by the aforementioned experimental areas.
} 
acknowledged by the main political parties that this programme must be kept. Our results provide insightful evidence about the benefits of the programme, particularly increasing the scientific impact of Spanish PRCs.

Our results are mainly limited by the data characteristics. On one side, they are not experimental but administrative data. On the other side, we are not certain about the status, in the four years after the call, of those non-granted researchers who are comparable with the beneficiaries. However, as we have documented earlier, they are most likely to remain linked to the PRCs in the evaluation period.

The programme is expected to have further positive effects beyond the increase in productivity of the beneficiaries. In particular, it would be interesting to study the spillover effects of the contracts on the scientific production of the PRCs. This is a promising extension that would require additional individual information of the researchers within PRCs to which the beneficiaries are affiliated.

\section{Acknowledgements}

We thank the Subdirección General de Formación y Movilidad del Personal Investigador (Spanish Office of Training and Mobility of Researchers) for providing the raw data and Miguel Benavente for assistance in data handling. Research funding from the Ministry of Finance and Competitiveness, Grant Nos. ECO2015-65204-P (Alonso-Borrego), ECO201457442P (Romero-Medina), ECO2015-70331-C2-1- R (SánchezMangas), MDM20140431 (Alonso-Borrego and RomeroMedina) and Comunidad de Madrid, Grant No. MadEco-CM S2015/HUM-3444 (all authors) is acknowledged. We thank Raquel Carrasco, Jesús Carro, Luis Sanz-Menéndez, audiences at the Simposium of the Spanish Economic Association, Vigo, December 2012, the Annual Conference of the European Economic Association, Gothenburg, August 2013, and the Conference of the European Association for Research in Industrial Economics, Evora, September 2013, for their comments.

\section{Disclosure statement}

No potential conflict of interest was reported by the authors.

\section{Funding}

This work was supported by the Ministry of Finance and Competitiveness: [Grant Nos. ECO2015-65204-P, ECO201457442P, ECO2015-70331-C2-1- R, MDM20140431] and
Comunidad de Madrid: [Grant No. MadEco-CM S2015/ HUM-3444].

\section{ORCID}

César Alonso-Borrego (b) http://orcid.org/0000-0003-49349134

Antonio Romero-Medina (D) http://orcid.org/0000-00024076-350X

Rocío Sánchez-Mangas (D) http://orcid.org/0000-0003-1379$851 \mathrm{X}$

\section{References}

Abadie, A., D. Drukker, J. L. Herr, and G. Imbens. 2004. "Implementing Matching Estimators for Average Treatment Effects in Stata." The Stata Journal 4 (3): 290-311.

Abadie, A., and G. Imbens. 2011. "Bias-Corrected Matching Estimators for Average Treatment Effects." Journal of Business \& Economic Statistics 29 (1): 1-11. doi:10.1198/ jbes.2009.07333.

Abadie, A., and G. W. Imbens. 2008. "On the Failure of the Bootstrap for Matching Estimators.” Econometrica 76 (6): 1537-1557. doi:10.3982/ECTA6474.

Abadie, A., and G. W. Imbens. 2009. Matching on the Estimated Propensity Score. Working Paper 15301. Cambridge, MA: National Bureau of Economic Research.

Alonso-Borrego, C., A. Romero-Medina, R. Sánchez-Mangas, and M. Triossi. 2013. "Boosting Scientific Research: Evidence from a Public Program." Revista de Economa Aplicada 21 (2): 115-128.

Arora, A., and A. Gambardella. 2005. "The Impact of NSF Support for Basic Research in Economics." Annales d'Économie et de Statistique 79: 91-117. doi:10.2307/ 20777571.

Arrow, K. 1962. " Economics Welfare and the Allocation of Resources for Invention." In The Rate and Direction of Inventive Activity, edited by $\mathrm{R}$. Nelson, 164-181. Princeton, NJ: Princeton University Press.

Beaudry, C., and S. Allaoui. 2012. "Impact of Public and Private Research Funding on Scientific Production: The Case of Nanotechnology." Research Policy 41 (9): 15891606. doi:10.1016/j.respol.2012.03.022.

Benavente, J. M., G. Crespi, L. Figal Garone, and A. Maffioli. 2012. "The Impact of National Research Funds: A Regression Discontinuity Approach to the Chilean FONDECYT." Research Policy 41 (8): 1461-1475. doi:10.1016/j.respol.2012.04.007.

Bosch, X. 2001a. "Tenure-Track Plan Aims to End University Inbreeding." Nature 410: 1014. doi:10.1038/35074267.

Bosch, X. 2001b. "Spain's Postdoc Plan Takes Off." Nature 413: 556. doi:10.1038/35098219.

Bosman, J., I. Van Mourik, M. Rasch, E. Sieverts, and H. Verhoeff. 2006. "Scopus reviewed and compared. The coverage and functionality of the citation database 
Scopus, including comparisons with Web of Science and Google Scholar." Utrecht: Utrecht University Library. http://igitur-archive.library.uu.nl/DARLIN/2006-1220200432/Scopus doorgelicht \& vergeleken - translated.pdf

Carayol, N., and M. Lanoe. 2013. "The Impact of Blue Skye Project Based Funding of Academic Research." mimeo. Université Bordeaux IV

Chudnovsky, D., A. López, M. A. Rossi, and D. Ubfal. 2008. "Money for Science? The Impact of Research Grants on Academic Output." Fiscal Studies 29 (1): 75-87. doi:10.1111/j.1475-5890.2008.00069.x.

CICIT - Comisión Interministerial de Ciencia y Tecnología, Ministerio de Ciencia y Tecnología. 2003. "The Spanish National Plan for Scientific Research Development and Technological Innovation for the period 2004-2007." Edited by Ministerio de Ciencia y Tecnología. http:// www.idi.mineco.gob.es/stfls/MICINN/Investigacion/ FICHEROS/ResumenPlan_InglesDocumentacion.pdf

Cruz-Castro, L., and L. Sanz-Menéndez. 2005. "Bringing Science and Technology Human Resources Back in: The Spanish Ramón y Cajal Programme." Science and Public Policy 32 (1): 39-53. doi:10.3152/147154305781779687.

Cruz-Castro, L., and L. Sanz-Menéndez. 2015. "Policy Change and Differentiated Integration: Implementing Spanish Higher Education Reforms." Journal of Contemporary European Research 11 (1): 103-123.

Dasgupta, P., and P. David. 1994. "Toward a New Economics of Science." Research Policy 23 (5): 487-521. doi:10.1016/ 0048-7333(94)01002-1.

DGI - Direccion General de Investigacion y Gestión del Plan Nacional de I+D+i. 2010. "10 años del Programa Ramón y Cajal" Secretaría de Estado de Investigación.” Ministerio de Ciencia e Innovación. http://www.idi.mineco.gob.es/stfls/ MICINN/Investigacion/FICHEROS/FicherosNotasPrensa/ ResultadosEncuesta10RyC\%20final_web.pdf

Fernández Esquinas, M. 2002. La formación de los investigadores cientficos en España. Madrid: Centro de Investigaciones Sociológicas-Siglo XXI Editores.

Harzing, A. W. 2007. "Publish or Perish."http://www.harz ing.com/pop.htm

Harzing, A. W. 2013. "A Preliminary Test of Google Scholar as a Source for Citation Data: A Longitudinal Study of Nobel Prize Winners." Scientometrics 93 (3): 1057-1075. doi:10.1007/s11192-012-0777-7.

Harzing, A. W., and R. van der Wal. 2008. "Google Scholar as a New Source of Citation Analysis." Ethics in Science and Environmental Politics 8 (1): 63-71. doi:10.3354/esep00076.

Jacob, B. A., and L. Lefgren. 2011. "The Impact of Research Grant Funding on Scientific Productivity." Journal of Public Economics 95 (9-10): 1168-1177. doi:10.1016/j. jpubeco.2011.05.005.

Jiménez-Contreras, E., F. de Moya Anegón, and E. Delgado López-Cózar. 2003. "The Evolution of Research Activity in Spain: The Impact of the National Commission for the Evaluation of Research Activity (CNEAI)." Research Policy 32 (1): 123-142. doi:10.1016/S0048-7333(02) 00008-2.

Moro-Martin, A. 2012. "Spanish Changes are Scientific Suicide." Nature 482: 277. doi:10.1038/482277a.

Muñoz-Pinedo, C., M. A. Del Pozo, J. A. Gálvez, E. M. Moreno, J. Buceta-Fernández, M. Garcia-Sanchez, J. M. Valdivielso, et al. 2003. "Spanish Scientists Working Abroad." Science 300 (5616): 51. doi:10.1126/ science. $300.5616 .51 \mathrm{~b}$.

Nelson, R. 1959. "The Simple Economics of Basic Scientific Research." Journal of Political Economy 67 (3): 297-306. doi:10.1086/258177.

OCT - Oficina de Ciencia y Tecnología. 1999. “ Plan Nacional de Investigación Científica, Desarrollo e Innovación Tecnológica (2000-2003)." Volumen I Objetivos y estructura. Presidencia del Gobierno Oficina de Ciencia y Tecnología, Ministerio de la Presidencia, Secretaría de Estado de la Comunicación. http://www.idi. mineco.gob.es/stfls/MICINN/Investigacion/FICHEROS/ pnidi-1.pdf

OECD, Organisation for Economic Co-operation and Development. 2007. Main Science and Technology Indicators. 2007 (1). doi:10.1787/msti-v2007-1-en-fr.

Rosenbaum, P. R., and D. B. Rubin. 1983. "The Central Role of the Propensity Score in Observational Studies for Causal Effects." Biometrika 70 (1): 41-55. doi:10.1093/biomet/70.1.41.

Sanz-Menéndez, L. 1997. Estado, ciencia y tecnología en España 1939-1997. Madrid: Alianza Universidad.

Sanz-Menéndez, L. 2003. "Coping with Researchers' Labour Market Problems Through Public Policy: The Spanish Ramón y Cajal Program"." In Fostering the Development of Human Resources for Science and Technology, Edited by Avveduto, S., 241-274. Roma: Biblink Editori.

Sanz-Menéndez, L., L. Cruz-Castro, and K. Alva. 2013. "Time to Tenure in Spanish Universities: An Even History Analysis." PLOS ONE 8 (10). doi:10.1371/journal. pone. 0077028.

Sanz-Menéndez, L., M. J. Jerez, A. Romero-Medina, I. Marqués, and A. Martnez. 2002. "Una nueva política de recursos humanos en I+D: El Programa Ramón y Cajal." Economía Industrial 343: 149-160.

Schiermeier, Q. 2004. "Spain Aims at Preimier League." Nature 431: 488-489. doi:10.1038/nj7007-488a.

Stewart, P., M. Ornstein, and J. Drakich. 2009. "Gender and Promotion at Canadian Universities." Canadian Review of Sociology 46 (1): 59-85. doi:10.1111/j.1755618X.2009.01203.x.

Wooldridge, J. M. 2002. Econometric Analysis of Cross Section and Panel Data. Cambridge, MA: MIT Press. 


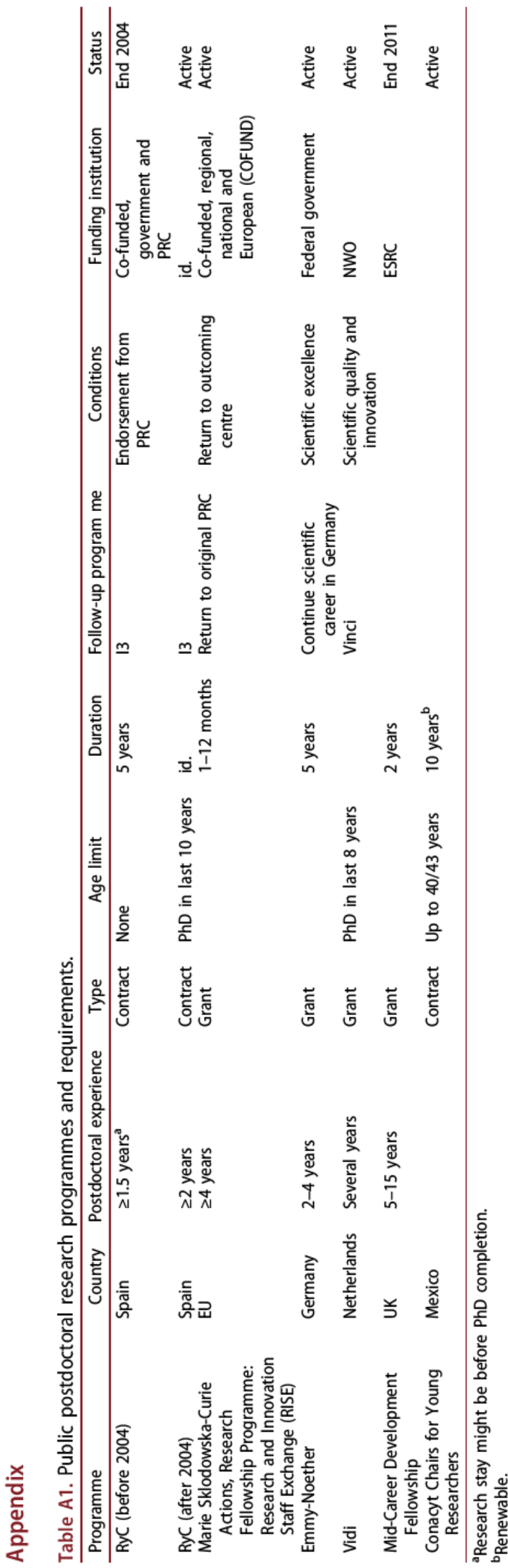

Table A2. Research areas and its correspondence with ANEP classification.

\begin{tabular}{ll}
\hline Area & \multicolumn{1}{c}{ ANEP classification } \\
\hline Physics & Physics and space sciences (1) \\
Earth sciences \& ecology & Earth sciences (2) \\
& Plant and animal biology, ecology (6) \\
Chemistry & Cheme and technology of materials (3) \\
& Chemical technology (5) \\
Agriculture, livestock \& & Agriculture (7) \\
fishery & Livestock and fishery (8) \\
& Food science and technology (9) \\
Biomedical sciences & Molecular and cell biology and genetics \\
& (10) \\
& Physiology and pharmacology (11) \\
& Medicine (12) \\
Engineering and computing & Mechanical, ship and aeronautical \\
science & engineering (13) \\
& Electric and electronic engineering (14) \\
& Civil engineering and architecture (15) \\
& Computing sciences and computer \\
& technology (17) \\
& Electronic and communications \\
technology (18) & Mathematics (16) \\
Mathematics & Economics, finance and business (19) \\
Economics & Law (20) \\
Social sciences \& law & Social sciences (21) \\
& Psychology and education sciences (22) \\
Arts \& humanities & Philology and philosophy (23) \\
& History and art (24) \\
\hline &
\end{tabular}

